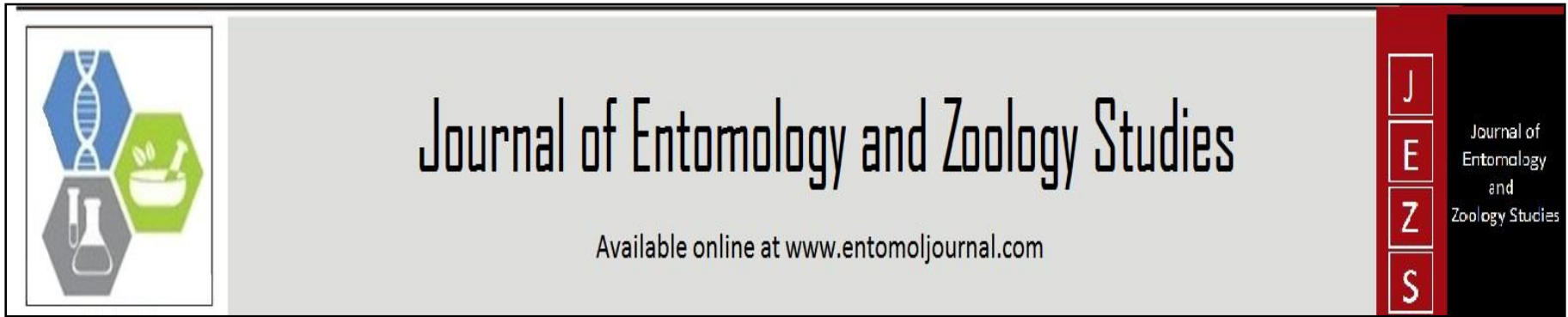

E-ISSN: 2320-7078 P-ISSN: 2349-6800 JEZS 2018; 6(1): 1582-1587 (C) 2018 JEZS

Received: 08-11-2017

Accepted: 09-12-2017

Mark Ian Cooper

University of South Africa, Pretoria, South Africa

\section{Sexual size dimorphism and the rejection of Rensch's rule in Diplopoda (Arthropoda)}

\author{
Mark Ian Cooper
}

\section{Abstract}

Rensch's rule predict the negative associations between sexual size dimorphism (SSD) and body sizes for relatively larger females. This prediction was tested for forest and savanna diplopods using a geometric morphometric approach using calculations of length and width to derive shape volume based on the mathematical formulae for estimated cylindrical worm-like millipede size $\left(l . \pi \cdot r^{2}\right)$ and spherical pill millipede size $\left(4 / 3 . \pi \cdot r^{3}\right)$ : (i) Centrobolus (were collected in February 1996, South Africa) SSD was 0.63$2.89(1.52 \pm 0.35$; 267) (ii) Sphaerotherium (extracted from literature) SSD was 1.49-5.36 (2.96 \pm 1.40 ; $\mathrm{n} \geq 7$ ); (iii) savanna (Calostreptus, Doratogonus, Odontopyge and Spinotarsus were collected in February 1989, Zimbabwe) and forest helminthomorphs (collected in February 1996, South Africa) SSD was 0.88$1.62(1.26 \pm 0.23 ; 1233)$. Interspecific variation regressed was SSD $(0.63-5.36)$ on body sizes $(n=1273)$ with no significant negative correlations rejecting Rensch's rule. Eco-morphological patterns were discussed.

Keywords: Allometry, Diplopoda, forest, myriapod, savanna

\section{Introduction}

Diplopoda are underrepresented in allometric analyses of sexual size dimorphism (SSD), although sexual size differences are known in body mass, length, width and leg dimensions of over half the taxa studied ${ }^{[1-6]}$. Size differences correlate with factors such as color, sexes, species, urbanisation and water relations ${ }^{[7-11]}$. Diplopoda resemble the majority of invertebrates where SSD is reversed ${ }^{[12]}$. SSD has consequences for outcomes of sexual encounters in diplopod mating ${ }^{[13-19]}$. The allometry of SSD involves the detection of a relationship between body size and SSD and is known by Rensch's rule ${ }^{[20-21]}$. Rensch's rule may be explained by sexual selection and fecundity selection ${ }^{[22-29]}$. The macro-evolutionary pattern is unresolved in Diplopoda ${ }^{[30]}$. Here, Rensch's rule was tested in predicting SSD was not negatively correlated with diplopod body size in African forest and savanna taxa. SSD in the forest genera Sphaerotherium and Centrobolus was investigated. The Sphaerotheriida genus Sphaerotherium consists of a large number of pill millipedes with some 54-60 described tropical and subtropical species extending to the Cape Peninsula in South Africa [31-33]. Individuals of both sexes roll into a spherical ball, which is part of the mating system [34]. Females are known to weigh up to three times more than males ${ }^{[35]}$. SSD has been studied in the Spirobolida genus Centrobolus with a relationship between the log of male and female volumes for 18 of 39 species suggesting corroboration of Rensch's rule ${ }^{[30]}$. SSD in the genus Centrobolus was re-investigated and re-tested. SSD in the savanna Spirostreptida genera Calostreptus, Doratogonus, Odontopyge and Spinotarsus were calculated from previously published data in Telford and Dangerfield ${ }^{[39]}$.

\section{Materials and Methods}

Up to three factors were measured from the sample of 2 infraclasses (Helminthomorpha and Pentazonia), 3 orders (Sphaerotheriida, Spirobolida, Spirostreptida), 4 families (Odontopygids, sphaerotheriids, spirostreptids, trigoniulids), 6 genera, and 36 species: (1) body length (mm) in placing individuals alongside a plastic rule (calibrated in $\mathrm{mm})$; (2) width $(\mathrm{mm})$ with Vernier calipers; and (3) mass (accurate to $0.01 \mathrm{~g}$ ) data was extracted from published data [36-40] Savanna helminthomorphs Calostreptus sp. (Hwange), Calostreptus sp. (Sengwe), Doratogonus (=Alloporus) uncinatus (Hwange), D. uncinatus (Mazowe), Odontopyge sp.2 (Marondera), Odontopyge sp.3 (Marondera), Odontopyge sp.3 (Vic. Falls) and Spinotarsus sp.1 (Marondera) were collected in Zimbabwe (February 1989).

\section{Correspondence}

Mark Ian Cooper

University of South Africa,

Pretoria, South Africa 
Forest helminthomorphs Centrobolus fulgidus (Richards' Bay Minerals), C. inscriptus (Mtunzini) and C. ruber (Anerley, Port Shepstone) were collected in South Africa (February 1996). Helminthomorph size was calculated as shape volume based on the formula for a cylinder $\left(l . \pi . r^{2}\right)$ where $l$ was body length and $r$ half of the width $i$. e . radius. Forest pentazonian body width $(\mathrm{mm})$ was extracted from Attems ${ }^{[40]}$ data on Sphaerotherium and size calculated as volume based on the formula for a sphere $\left(4 / 3 . \pi . r^{3}\right)$ where $r$ was the radius. In both helminthomorph and pentazonians, SSD was estimated as the mean female volume divided at mean male volume and converted into a SSD index by subtracting $1^{[41]}$. Allometry for SSD was based on a general allometric model where male size $=\alpha(\text { female size })^{\beta[42-45]}$.

\subsection{Statistical Analysis}

SSD were calculated using Microsoft Office Excel mathematical and statistical formula. Male and female widths were either halved, cubed and multiplied at pi using a combination of mental arithmetic, power and product functions (pill millipedes) or halved, squared and multiplied at pi and length using the same approach (worm-like millipedes). Once calculated, species body size measurements were treated as the independent $\mathrm{x}$-variable or factor and measurements of SSD derived from ratios of female volumes divided at male volumes were treated as the dependent yvariables and were inserted into: Spearman's Rho online calculator

(http://www.socscistatistics.com/tests/spearman/Default2.asp $\mathrm{x})$. Similarly for the linear regression mass, volume and SSD were inserted into the online calculator (http://www.socscistatistics.com/tests/regression/Default.aspx).
Calculations were performed for (1) a Spirobolida data set which included Centrobolus volumes and SSD on taxa collected as Cooper ${ }^{[36]}$, (2) a Sphaerotheriida data set which included Sphaerotherium volumes and SSD on taxa collected by Attems [40], and (3) a Spirostreptida data set which included the four savanna genera collected in Telford and Dangerfield ${ }^{[42]}$. A second correlation analysis was performed on all 3 groups using Pearson's correlation coefficient analysis to test for negative correlations between size and SSD. Additional analysis included (4) Helminthomorphs (forest and savanna together) and (5) forest taxa (Centrobolus and Sphaerotherium).

\section{Results}

The allometric equation for Centrobolus was (1) $\hat{y}=$ $0.00051 X-0.01071$. SSD ranged from $0.63-2.89(1.55 \pm$ $0.63 ; \mathrm{n} \geq 18)$ and was not negatively correlated $(\mathrm{R}=0.70485$; $\mathrm{P}=0.00109 ; \mathrm{n}=18 \mathrm{spp}$.) with volume ranging from $284-$ $2683 \mathrm{~mm}^{3}$ (1097.89 $\left.\pm 638.06 ; 18\right)$ (Table 1). The allometric equation for Sphaerotherium was (2) $\hat{\mathrm{y}}=0.00045 \mathrm{X}+$ 1.38384. SSD ranged from $1.49-5.36(2.96 \pm 1.40 ; \mathrm{n} \geq 7)$ and was not negatively correlated $(\mathrm{R}=0.46429 ; \mathrm{P}=0.29393$; $\mathrm{n}=7$ spp.) with volume ranging from $224-2877 \mathrm{~mm}^{3}$ $(1299.43 \pm 1127.84 ; 7)$ (Table 2). The allometric equation for the mixed sample of savanna and forest helminthomorphs was (3) $\hat{y}=-0.03795 X+1.34816$. In the sample of savanna and forest worm-like diplopods SSD ranged from $0.88-1.62$ (Mean $\pm \mathrm{SD}=1.26 \pm 0.23 ; \mathrm{n}=1233$ ) and no significant negative correlations $(\mathrm{R}=-0.230594 ; \mathrm{P}=0.49513 ; \mathrm{n}=11$ spp.) were found with mass ranging from $0.75-8.30 \mathrm{~g}(2.42$ \pm 2.57 ; 1233) (Table 3)

Table 1: Body size, sexual size dimorphism (SSD) and SSD index for Centrobolus Cook.

\begin{tabular}{|c|c|c|c|c|}
\hline Species & Body size $\left(\mathbf{m m}^{\mathbf{3}}\right)$ & SSD & SSD-1 & Sample size (n) \\
\hline C. albitarsus & 952 & 2.89 & 1.89 & 1 \\
\hline C. decoratus & 557 & 0.63 & -0.37 & 1 \\
\hline C. digrammus & 522 & 1.01 & 0.01 & 6 \\
\hline C. dubius & 1210 & 1.35 & 0.35 & 1 \\
\hline C. fulgidus & 1518 & 1.65 & 0.65 & 22 \\
\hline C. fulgidus & $1.65 \mathrm{~g}$ & 1.25 & 0.25 & 1 \\
\hline C. immaculatus & 1580 & 2.72 & 1.72 & 176 \\
\hline C. inscriptus & $2.38 \mathrm{~g}$ & 1.22 & 0.22 & 1 \\
\hline C. inyanganus & 775 & 1.44 & 0.44 & 1 \\
\hline C. lawrencei & 962 & 1.57 & 0.57 & 1 \\
\hline C. lugubris & 2046 & 2.18 & 1.18 & 1 \\
\hline C. promontories & 284 & 0.69 & -0.31 & 36 \\
\hline C. pusillus & 756 & 2.08 & 1.08 & 1 \\
\hline C. ruber & $1.64 \mathrm{~g}$ & 1.62 & 0.62 & 1 \\
\hline C. rugulosus & 1666 & 1.97 & 0.97 & 1 \\
\hline C. sagatinus & 1659 & 1.27 & 0.27 & 1 \\
\hline C. silvanus & 749 & 1.13 & 0.13 & 1 \\
\hline C. titanophilus & 393 & 1.15 & 0.15 & 1 \\
\hline C. transvaalicus & 669 & 1.26 & 0.26 & \\
\hline C. tricolor & 781 & 1.10 & 0.10 & \\
\hline C. vastus & 2683 & 1.81 & 0.81 & \\
\hline
\end{tabular}

Table 2: Body size, sexual size dimorphism (SSD) and SSD index in Sphaerotherium Brandt 1833.

\begin{tabular}{|c|c|c|c|c|}
\hline Species & Body Size $\left(\mathbf{m m}^{\mathbf{3}}\right)$ & SSD & SSD-1 & Sample size (n) \\
\hline S. cinctellum & 2660 & 1.73 & 0.73 & 1 \\
\hline S. commune & 281 & 3.97 & 2.97 & 1 \\
\hline S. compressum & 1501 & 3.62 & 2.62 & 1 \\
\hline S. punctulatum & 2877 & 5.36 & 4.36 & 1 \\
\hline S. spinatum & 1282 & 2.21 & 1.22 & 1 \\
\hline S. tenuitarse & 224 & 1.49 & 0.49 & 1 \\
\hline S. tuberosum & 271 & 2.37 & 1.37 & 1 \\
\hline
\end{tabular}


Table 3: Body size, SSD and SSD index for savanna worm-like millipedes (localities in parentheses).

\begin{tabular}{|c|c|c|c|c|}
\hline Species & Body Size (g) & SSD & SSD-1 SSD-1 & Sample size (n) \\
\hline Calostreptus sp. (Hwange) & 1.10 & 1.50 & 0.50 & 70 \\
\hline Calostreptus sp. (Sengwe) & 0.75 & 1.50 & 0.50 & 58 \\
\hline Doratogonus uncinatus (Hwange) & 8.30 & 1.08 & 0.08 & 54 \\
\hline D. uncinatus (Mazowe) & 6.65 & 0.99 & -0.01 & 521 \\
\hline Odontopyge sp.2 (Marondera) & 1.14 & 1.36 & 0.36 & 117 \\
\hline Odontopyge sp.3 (Marondera) & 1.40 & 1.29 & 0.29 & 44 \\
\hline Odontopyge sp.3 (Victoria Falls) & 0.85 & 1.13 & 0.13 & 83 \\
\hline Spinotarsus sp.1 (Marondera) & 0.75 & 0.88 & -0.13 & 52 \\
\hline
\end{tabular}

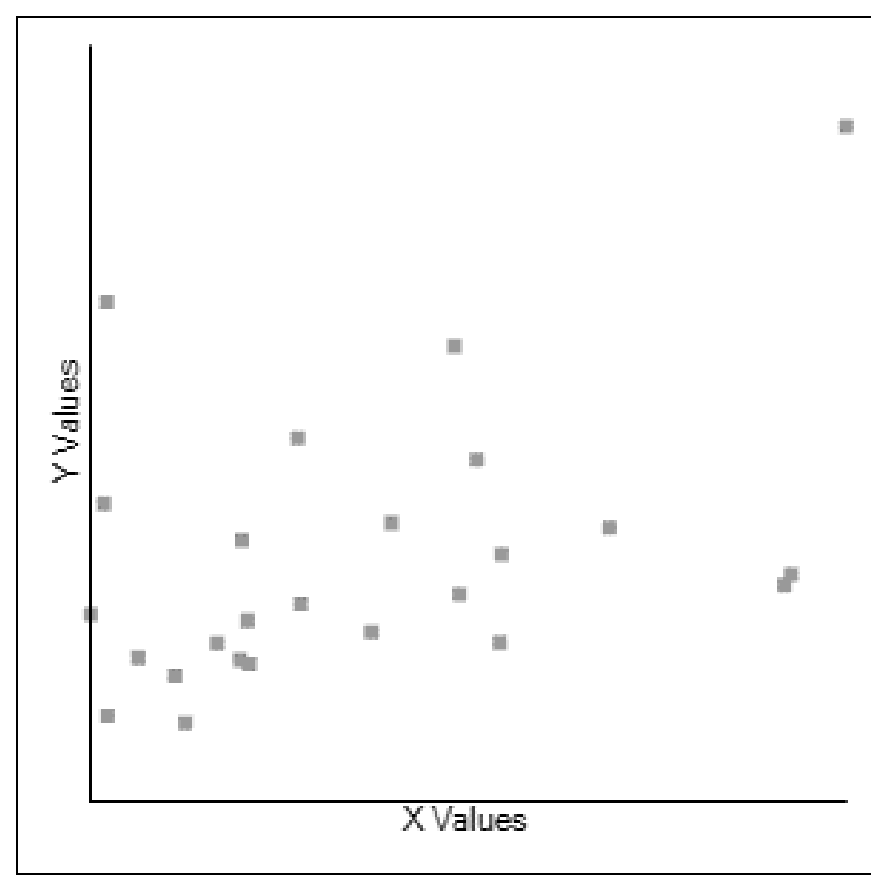

Fig 1: Scatterplot showing the positive correlation between sexual size dimorphism (SSD) and body sizes for forest diplopods including Centrobolus and Sphaerotherium.

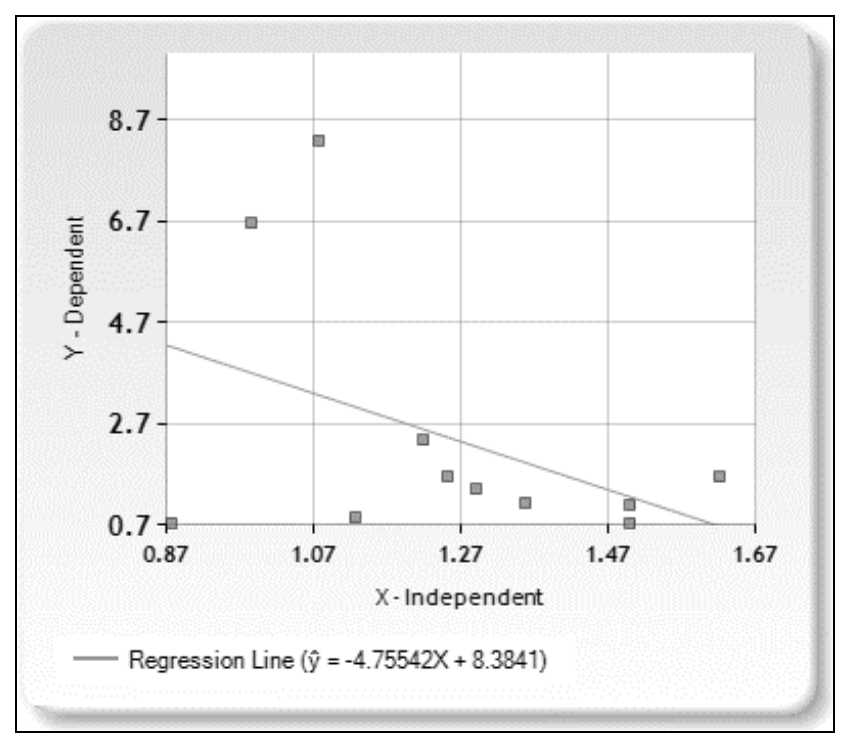

Fig 2: Scatterplot showing the negative correlation between sexual size dimorphism (SSD) and body sizes for savanna diplopods including Calostreptus, Doratogonus, Odontopyge and Spinotarsus sp.1

\section{Discussion}

Allometric equations for (1) Centrobolus was positively correlated but not negatively; (2) Sphaerotherium was positively correlated but not significant; and (3) the mixed sample of savanna and forest helminthomorphs show body sizes and SSD was negatively correlated but not significantly.
Also, further analysis of (4) helminthomorphs, and (5) forest taxa showed no significant negative correlations. All 3 equations of relationships between SSD and body mass from the sample of 36 species of diplopods showed there was no significant negative correlations between SSD and body sizes. Rensch's rule was re-assessed in Centrobolus forest diplopods and no supporting evidence produced. However, mass and volume do not provide equal measures of SSD. In the case where both mass and volume were measured ( $C$. fulgidus) this was evident ${ }^{[46]}$. In order to obtain more accurate results, the analysis for (1) and (2) included only volume (Fig. 1) while the analysis for (3) included solely mass measurements (Fig. 2). In the savanna millipedes the genus Spinotarsus showed male-biased sexual dimorphism. Three mass measurements of Centrobolus were included in the worm-like analysis. So, regressions between body sizes and SSD calculated here for 3 types of diplopods indicated no evidence for Rensch's rule. Sexual size dimorphism appears to be higher for forest millipedes than the savanna millipedes. However, this Eco morphology is probably due to the greater variation of the forest millipedes which has evolved through climate change as is the case of refugial speciation with the forest Sphaerotherium representing the palaeotaxa ${ }^{[47]}$. Forest taxa illustrate differences in morphology and species composition [48]. Tree-climbing behaviour in several species suggests interspecific competition drives SSD ${ }^{[49]}$.

Numerous studies are finding animal taxa having female biased SSD mostly disobey Rensch's rule including many of the invertebrates and frogs as well as a plethora of animal taxa [50-73]. A recent study on the European millipede Pachyiulus hungaricus shows "[s]ize and/or shape of the morphological traits (except the shape of male walking legs) used in our study were not subject to pre-copulatory sexual selection." [74] The absence of any relationships between size and mating was documented for the tropical millipede Nyssodesmus pythos ${ }^{[13]}$. My evidence for sexual selection on dimorphism is based on the relative size dimorphism in Centrobolus which shows size is important in determining the outcome of mating $[47,73,76-77]$. The mechanism is based on a conflict of interests [77]. In the millipede Doratogonus uncinatus female choice for mating partners is "size selective" ${ }^{[78]}$. The cross-mating experiments in Centrobolus suggest a combination of size assortative mating without a size based preference operates [79].

Further studies of diplopod sexual dimorphism may include more taxa and make use of the length and width measurements to calculate volumes using the geometric morphometric approach shown here for finding causal relationships of dimorphism. The sexual dimorphism calculated here may be converted into alternative indices of sexual dimorphism in order to update its relevance, e. g. M I index $[80,81]$. It is worth noting sexual dimorphism and the selection pressures may be decoupled in time $e$. $g$. ostracodes [82]. Geometric morphometrics is useful for converting the 
shape into size ${ }^{[83]}$. Future goal is to compile the allometry for SSD for the diplopod fauna from South African savanna and forest biomes where a diversity of species has been documented to exist ${ }^{[84,85]}$.

\section{Conclusion}

Sphaerotheriida, Spirobolida and Spirostreptida SSD does not negatively regress with body sizes but break Rensch's rule. Intersexual competition is believed to drive SSD in diplopods with forest taxa containing the diversity of species and sizes. A geometric morphometric approach successfully determined the shape and size of millipedes which enabled us to see a relationship, or lack hereof, between shape as size and SSD. The inverse of Rensch's rule was found in Centrobolus based on the relationship between SSD and body size.

\section{Acknowledgements}

Hans Riep made MyriaLit data base available. University of South Africa student number 58536396.

\section{References}

1. Cooper MI. Heavier-shorter-wider females in the millipede Centrobolus inscriptus (Attems). Journal of Entomology and Zoology Studies 2016; 4(2):509-510.

2. Hopkin SP, Read HJ. The Biology of Millipedes. Oxford University Press, U. K., 1992, 246.

3. Ilić BS, Mitić BM, Makarov SE. Sexual dimorphism in Apfelbeckia insculpta (L. Koch, 1867) (Myriapoda: Diplopoda: Callipodida). Archives of Biological Sciences 2017; 69:23-33.

4. Wilson HM, Anderson LI. Morphology and taxonomy of Paleozoic millipedes (Diplopoda: Chilognatha: Archipolypoda) from Scotland. Journal of Paleontology 2004; 78(1):169-184.

5. Telford SR, Dangerfield JM. Sex in millipedes: laboratory studies on sexual selection. Journal of Biological Education 1990; 24:233-238.

6. Sota T, Tanabe T. Multiple speciation events in an arthropod with divergent evolution in sexual morphology. Proceedings of the Royal Society B: Biological Sciences 2010; 277(1682):689-696.

7. Bhakat S. Comparative water relations of some tropical millipedes. Kragujevac Journal of Science. 2014; 36:185194.

8. Bogyó D, Magura T, Simon E, Tóthmérész B. Millipede (Diplopoda) assemblages alter drastically by urbanisation. Landscape and Urban Planning. 2015; 133:118-126.

9. Calligaris IB, Boccardo L, Sanches MR, Fontanetti CS. Morphometric Analysis of a Population of Diplopods of the Genus Rhinocricus Karsch, 1881. Folia Biologica (Praha) 2005; 51:40-46.

10. David JF. Size criteria for the distinction between Cylindroiulus londinensis (Leach) and Cylindroiulus caeruleocinctus (Wood) (Diplopoda: Julidae). Journal of Natural History 1995; 29:983-991.

11. Enghoff H. The size of a millipede. In: Meyer E, Thaler $\mathrm{K}$, Schedl W (eds.) Advances in Myriapodology. Berichte des naturwissenschaftlich-medizinischen Vereins in Innsbruck, Supplement 1992; 10:47-56.

12. Mori E, Mazza G, Lovari S. Sexual Dimorphism. In: Encyclopedia of Animal Cognition and Behavior ( $\mathrm{J}$. Vonk, and T. Shakelford, Eds). Springer International Publishing, Switzerland, 2017, 1-7.

13. Adolph SC, Geber MA. Mate-Guarding, Mating Success and Body Size in the Tropical Millipede 'Nyssodesmus Pythos' (Peters) (Polydesmida: Platyrhacidae). The Southwestern Naturalist. 1995; 40(1):56-61.

14. Rowe M. Copulation, mating system and sexual dimorphism in an Australian millipede, Cladethosoma clarum. Australian Journal of Zoology. 2010; 58(2):127132.

15. Cooper MI Size matters in myriapod copulation. Journal of Entomology and Zoology Studies 2017; 5(2):207-208.

16. Tanabe T, Sota T. Complex Copulatory Behavior and the Proximate Effect of Genital and Body Size Differences on Mechanical Reproductive Isolation in the Millipede Genus Parafontaria. The American Naturalist. 2008; 171(5):692-699.

17. Cooper MI. The effect of female body width on copulation duration in Centrobolus inscriptus (Attems). Journal of Entomology and Zoology Studies. 5(1):732733.

18. Holwell GI, Allen PJD, Goudie F, Duckett PE, Painting CJ. Male density influences mate searching speed and copulation duration in millipedes (Polydesmida: Gigantowales chisholmi). Behavioural Ecology and Sociobiology. 70(8):1381-1388.

19. Akkari N, Enghoff H. Copulatory-copulatory male succession and male slenderness in Ommatoiulus sempervirilis n. sp., a new insular millipede from Tunisia (Diplopoda: Julida: Julidae). Journal of Zoological Systematics and Evolutionary Research. 2011; 49(4):285291.

20. Rensch B. Evolution above the Species Level. Columbia, New York, 1947, 419.

21. Rensch B. Die Abhängigkeit der relativen Sexualdifferenz von der Körpergrösse. Bonn Zoological Bulletin. 1950; 1:58-69.

22. Andersson M, Wallander J. Animal behaviour: Relative size in the mating game. Nature. 2004; 431:139-141.

23. Bonduriansky R. Sexual selection and allometry: A critical reappraisal of the evidence and ideas. Evolution. 2007; 61(4):838-849.

24. Clutton-Brock TH, Harvey PH, Rudder B. Sexual dimorphism, socionomic sex ratio and body weight in primates. Nature. 1977; 269:797-800.

25. Dale J, Dunn PO, Figuerola J, Lislevand T, Székely T, Whittingham LA. Sexual selection explains Rensch's rule of allometry for sexual size dimorphism. Proceedings of the Royal Society B. 2007; 274:2971-2979.

26. Gaulin SJC, Sailer LD. Sexual dimorphism in weight among the Primates: the relative impact of allometry and sexual selection. International Journal of Primatology 1984; 5(6):515-535.

27. Pincheira-Donoso D, Hunt J. Fecundity selection theory: concepts and evidence. Biological Reviews. 2015; 92:341-356.

28. Cooper MI. Sexual bimaturism in the millipede Centrobolus inscriptus (Attems). Journal of Entomology and Zoology Studies. 2016; 4(3):86-87.

29. Andersson M. Sexual Selection. Princeton University Press, 1994, 624.

30. Cooper MI Sexual size dimorphism and corroboration of Rensch's rule in Chersastus millipedes. Journal of Entomology and Zoology Studies. 2014; 2(6):264-266.

31. Van den Spiegel D, Golovatch SI, Hamer ML. Revision of some of the oldest species in the millipede genus Sphaerotherium Brandt, 1833 (Diplopoda, Sphaerotheriida, Sphaerotheriidae), with new 
synonymies. African Invertebrates. 2002; 43:143-181.

32. Cooper MI. Pill millipedes. African Wildlife, 58(2):44.

33. Wesener T. The Giant Pill-Millipedes, order Sphaerotheriida - An annotated species catalogue with morphological atlas and list of apomorphies (Arthropoda: Diplopoda). Bonn zoological Bulletin - Supplementum. 2016, 63:1-104.

34. Wesener T, Köhler J, Fuchs S, Van den Spiegel D. How to uncoil your partner- "mating songs" in giant pillmillipedes (Diplopoda: Sphaerotheriida). Naturwissenschaften. 2011; 98:967-975.

35. Carrel JE. Defensive secretion of the pill millipede Glomeric marginata. Journal of Chemical Ecology. 1984; 10(1):41-51.

36. Cooper MI. Copulation and sexual size dimorphism in worm-like millipedes. Journal of Entomology and Zoology Studies. 2017; 5(3):1264-1266.

37. Cooper MI. Allometry of copulation in worm-like millipedes. Journal of Entomology and Zoology Studies. 2017; 5(3):1720-1722.

38. Schubart O, Diplopoda III. South African Animal Life 1966; 12:1-227.

39. Telford SR, Dangerfield JM. Mating behaviour and mate choice experiments in some tropical millipedes (Diplopoda: Spirostreptidae). African Zoology. 1993; 28(3):155-160.

40. Attems C. The Myriapoda of South Africa. Annals of the South African Museum. 1928; 26:1-431.

41. Lovich JE, Gibbons JW. A review of techniques for quantifying sexual size dimorphism. Growth Development and Aging. 1992; 56:269-281.

42. Gould SJ. Allometry and size in ontogeny and phylogeny. Biological Reviews 1966; 41:587-640.

43. LaBarbera M. Analyzing body size as a factor in ecology and evolution. Annual Review of Ecology and Systematics. 1989; 20:97-117.

44. Leutenegger W. Scaling of sexual dimorphism in body size and breeding system in primates. Nature. 1978; 272(5654):610-611.

45. West GB, Brown JH, Enquist BJ. A General Model for the Origin of Allometric Scaling Laws in Biology. Science. 1997; 276:122-126.

46. Cooper MI. Relative sexual size dimorphism in Centrobolus fulgidus (Lawrence) compared to 18 congenerics. Journal of Entomology and Zoology Studies. 2017; 5(3):77-79.

47. Tolley KA, Tilbury CR, Measey GJ, Menegon M, Branch WR, Matthee CA. Ancient forest fragmentation or recent radiation? Testing refugial speciation models in chameleons within an African biodiversity hotspot. Journal of Biogeography. 2011; 38(9):1748-1760.

48. Hamer M, Slotow R. A comparison and conservation assessment of the high-altitude grassland and forestmillipede (Diplopoda) fauna of the South African Drakensberg. Soil Organisms. 2009; 81(3):701-717.

49. Haacker U, Fuchs S. Tree-Climbing in pill-millipedes. Oecologia 10(2):191-192.

50. Lindenfors P, Tullberg BS, Biuw M. Phylogenetic analyses of sexual selection and sexual size dimorphism in pinnipeds. Behavioural Ecology and Sociobiology. 2002; 52:188-193.

51. Monnet JM, Cherry MI. Sexual size dimorphism in anurans. Proceedings of the Royal Society of London B Biological Sciences. 2002; 269(1507):2301-2307.

52. Jannot JE, Kerans BL. Body size, sexual size dimorphism, and Rensch's rule in adult hydropsychid caddisflies (Trichoptera: Hydropsychidae). Canadian Journal of Zoology. 2003; 81:1956-1964.

53. Tubaro PL, Bertelli S. Female-biased sexual size dimorphism in tinamous: A comparative test fails to support Rensch's rule. Biological Journal of the Linnean Society. 2003; 80:519-527.

54. Rutherford PL. Proximate mechanisms that contribute to female-biased sexual size dimorphism in an anguid lizard. Canadian Journal of Zoology. 2004; 82(5):817822.

55. Teder T, Tammaru T. Sexual size dimorphism within species increases with body size in insects. Oikos. 2005; 108:321-334.

56. Webb TJ, Freckleton RP. Only Half Right: Species with Female-Biased Sexual Size Dimorphism Consistently Break Rensch's Rule. PLoS ONE. 2007; 2(9):e89715.

57. Sutter NB, Mosher DS, Ostrander EA. Morphometrics within dog breeds are highly reproducible and dispute Rensch's rule. Mammalian Genomics. 2008; 19:713-723.

58. Stuart-fox D. A test of Rensch's rule in dwarf chameleons (Bradypodion spp.), a group with femalebiased sexual size dimorphism. Evolutionary Ecology. 2009; 23:425-433.

59. Herczeg G, Gonda A, Merilä J. Rensch's rule inverted female-driven gigantism in nine-spined stickleback Pungitius pungitius. Journal of Animal Ecology. 2010; 79:581-588.

60. Remeš V, Székely T. Domestic chickens defy Rensch's rule: sexual size dimorphism in chicken breeds. Journal of Evolutionary Biology. 2010; 23:2754-2759.

61. Minton RL, Wang LL. Evidence of sexual shape dimorphism in Viviparus (Gastropoda: Viviparidae). Journal of Molluscan Studies. 2011; 77(3):315-317.

62. Liao WB, Chen W. Inverse Rensch-rule in a frog with female-biased sexual size dimorphism. Naturwissenschaften. 2012; 99:427-431.

63. Bidau CJ, Martí DA, Castillo ER. Rensch's rule is not verified in melanopline grasshoppers (Acrididae). Journal of Insect Biodiversity. 2013; 1(12):1-14.

64. De Lisle SP, Rowe L. Correlated Evolution of Allometry and Sexual Dimorphism across Higher Taxa. The American Naturalist. 2013; 182(5):630-639.

65. Liao WB, Zeng Y, Zhou CQ, Jehle R. Sexual size dimorphism in anurans fails to obey Rensch's rule. Frontiers in Zoology. 2013; 10(10):1-7.

66. Liao WB. Evolution of sexual size dimorphism in a frog obeys the inverse of Rensch's rule. Evolutionary Biology. 2013; 40:493-499.

67. Colleoni E, Denoël M, Padoa-Schioppa E, Scali S, Ficetola GF. Rensch's rule and sexual dimorphism in salamanders: patterns and potential processes. Journal of Zoology. 2014; 293:143-151.

68. Guillermo-Ferreira R, Novaes MC, Lecci LS, Bispo PC. Allometry for Sexual Size Dimorphism in Stoneflies Defies the Rensch's Rule. Neotropical Entomology. 2014; 43:172.

69. Husak JF, McGuire JA. Does 'gliding while gravid' explain Rensch's rule in flying lizards? Biological Journal of the Linnean Society. 2014; 113:270-282.

70. Lu D, Zhou CQ, Liao WB. Pattern of sexual size dimorphism supports the inverse Rensch's rule in two frog species. Animal Biology. 2014; 64:87-95.

71. Liao, WB, Liu WC, Merilä J. Andrew meets Rensch: sexual size dimorphism and the inverse of Rensch's rule 
in Andrew's toad (Bufo andrewsi). Oecologia. 2015; 177:389-399.

72. Cooper MI. The relative sexual size dimorphism of Centrobolus inscriptus (Attems) compared to 18 congenerics. Journal of Entomology and Zoology Studies. 2016; 4(6):504-505.

73. Martin OY, Michalczyk L, Millard AL, Emerson BC, Gage MJG. Lack of support for Rensch's rule in an intraspecific test using red flour beetle (Tribolium castaneum) populations. Insect Science. 2017; 24(1):133140.

74. Javonovic Z, Pavković-Lučić S, Ilić B, Vujić V, Dudić B, Makarov $\mathrm{S}$ et al. Mating behaviour and its relationship with morphological features in the millipede Pachyiulus hungaricus (Karsch, 1881) (Myriapoda, Diplopoda, Julida). Turkish Journal of Zoology. 2017; 41:1010-1023.

75. Cooper MI. Relative sexual size dimorphism in Centrobolus digrammus (Pocock) compared to 18 congenerics. Journal of Entomology and Zoology Studies. 2017; 5(2):1558-1560.

76. Cooper MI. Relative sexual size dimorphism Centrobolus ruber (Attems) compared to 18 congenerics. Journal of Entomology and Zoology Studies. 2017; 5(3):180-182.

77. Cooper MI. Sexual conflict over the duration of copulation in Centrobolus inscriptus (Attems). Journal of Entomology and Zoology Studies. 2016; 4(6):852-854.

78. Telford SR, Dangerfield, JM. Mating Tactics in the Tropical Millipede Alloporus uncinatus (Diplopoda: Spirostreptidae). Behaviour. 1993; 124:45-56.

79. Cooper MI. Fire millipedes obey the female sooner norm in cross mating Centrobolus (Myriapoda). Journal of Entomology and Zoology Studies. 2016; 4(1):173-174.

80. Ipiña SL, Durand AI. A measure of sexual dimorphism in populations which are univariate normal mixtures. Bulletin of Mathematical Biology. 2000; 62:925-941.

81. Ipiña SL, Durand AI. Inferential assessment of the MI index of sexual dimorphism: A comparative study with some other sexual dimorphism measures. Bulletin of Mathematical Biology. 2004; 66:505-522.

82. Yamaguchi T, Honda R, Matsui H, Nishi H. Sexual shape dimorphism and selection pressure on males in fossil ostracodes. Paleobiology. 2017; 43(3):407-424.

83. Benítez HA. Sexual Dimorphism Using Geometric Morphometric Approach. Chapter 3. In: Sexual Dimorphism, Moriyama H, Intech, 2013.

84. Druce D, Hamer M, Slotow R, Prendini L. Checklist of millipedes (Diplopoda), centipedes (Chilopoda) and scorpions (Arachnida: Scorpionida) from a savanna ecosystem, Limpopo Province, South Africa. African Invertebrates. 2004; 45:315-322.

85. Hamer ML. Checklist of Southern African millipedes (Myriapoda: Diplopoda). Annals of the Natal Museum. 1998; 39(1):11-82. 